\title{
Relationship of Organizational Behavior and Students’ Emotional Quotient
}

\author{
Elymar A. Pascual \\ elymarpascual@rocketmail.com \\ Department of Education, Nagcarlan, Laguna, Philippines 4002
}

\begin{abstract}
This study focused on the relationship of organizational behavior of United Evangelical Christian School (UECS), Sta. Cruz, Laguna, and students' emotional quotient. It also includes assessment of students' multiple intelligences and learning styles as moderating variables. In going on with the study, the researcher made use of descriptive-survey design. Nineteen teaching and non-teaching faculty participated in the organizational behavior survey, while 134 students from grade 4 to $4^{\text {th }}$ year became the subject of emotional quotient (EQ), multiple intelligences (MI) and learning styles (LS) assessment test. For organizational behavior, EQ, MI and LS, simple mean and percentage were used to answer the specific problems posed at the beginning of the study. On the other hand, t-test was used to know the relationship of organizational behavior to each of the five dimensions emotional quotient, namely: self-awareness, self-regulation, motivation, empathy and social skills. It was found out that UECS management, faculty and employee prefer collegial mode, more than supportive, autocratic and custodial mode of organizational behavior, as evidenced by their average rating of 3.89 (frequent). In terms of emotional quotient, $64.18 \%$ of the students already have "self-awareness" competency, 56.72\% already have "self-regulation" competency, 53.73\% already have "motivation" competency, 52.99\% already have "empathy" competency, and 63,43\% already have "social skills" competency. In terms of multiple intelligences, $41.04 \%$ of the students are inclined in linguistics, $19.40 \%$ of the students have kinesthetic ability, $24.63 \%$ are inclined with intrapersonal relationship, 39.55\% are inclined in mathematical, $31.34 \%$ are inclined in musically, $50.75 \%$ are naturalists, $29.85 \%$ have spatial ability, and $37.31 \%$ are inclined with interpersonal relationship. In terms of learning styles, 103 out of 134 students (76.87\%) are leftbrain hemisphere oriented, while 31 out of 134 (23.13\%) of the students are right-brain hemisphere oriented. Using statistical test, it was found out that organizational behavior has significant relationship to each of the five dimensions of emotional quotient. Because of this, this paper recommends that UECS management, faculty and employees maintain their team concept in building management-employee partnership for it will boost up the development of emotional quotient of the students.
\end{abstract}

Keywords: organizational behavior; autocratic; custodial; supportive; collegial; emotional quotient; social awareness; self-regulation; motivation; empathy; social skills

\section{Introduction}

"A teacher affects eternity; he can never tell where his influence stops."

Henry Brooks Adams

Just a few months ago, world news dumbfound education sector about a Korean student putting 31 people in hostage and afterwards committing suicide. In his self-made video before he died, he was complaining about the current norm of society, his dismay on how the poor are treated, and the negligence of government in dealing with social problems. Psychologists declared that his immediate environment triggered his misbehavior, causing the death of some students in the university where he is enrolled.

As Henry Adams declared, it is generally accepted that teachers greatly affect the students they are handling, not only the present but also the future of the students. Teachers should be aware of the things, ideas and values they are modeling for they are easily caught than taught. Students, especially youth are always eager to try doing the things they are seeing in their immediate environment without too much consideration or deliberation if it is good to them or not. All they know is that they observed it and they think fine with the society where they belong.

But it is not only the teachers that the students observed almost everyday of their life. The school organization and how it behaves is also an open book to them. We may never know but it matters to them how the managers of the school relate to the employees and faculty, and vice versa. If there are conflicts or skirmishes within the organization, the students may not know the whole detail but they sense it, at least. Therefore, they emotional development is at stake.

Few, if none, studies have been conducted with regards to the effect or relationship of organizational behavior to the emotional quotient of the students. With the present scenario of how the youth behave inside or outside the school, is it possible that the school's organizational behavior has something to do with the students' emotional quotient? If there is, what dimension of emotional quotient does organizational behavior affect?

\subsection{Background of the Study}




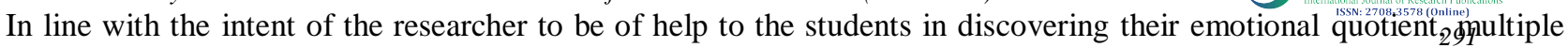
intelligences and leaning styles, the writer together with the enabling help of the guidance counselor conducted a series of assessments that will elicit such data needed in this study. Believing that organizational behavior has something to do with the emotional quotient of the students, the researcher decided to make a survey that will show what mode of organizational behavior does the United Evangelical Church School (UECS) prefers.

The UECS is a non-denominational and non-sectarian learning institution with a Christ-centered and Bible-based perspective. The school is committed to providing education for the development of the youth in all aspects of life; striving for excellence in knowledge, effective character development and to nurture their talents for a higher service to God and mankind.

The school started as a vision given to the church board of United Evangelical Church at A. Regidor St., Sta. Cruz, Laguna in the year 1993. At first, it was just a learning center, taking a small space inside the church. As years went by and the children grew up, more and more rooms were needed and they have to transfer to a bigger lot. The space in front of Laguna State Polytechnic University (Laguna College of Arts and Trade at that time) was proved to be given by God as more and more children enrolled. And now, the school grow up to its present population of 361 students from preschool to high school.

The school has the following profile:

1.) Student Development

a.) Christ-centered and Bible based perspective - The school has its primary distinction in being a school which is Christ-centered and therefore has its core values and perspective coming from the Bible. It exist because of the Church Mission which is found in Matthew 28:18-20.

b.) Character Development - UECS is a Christian school which provide academic subjects, and not the other way around - academic school which teaches religion. That's why character development is its primary concern in serving its clients.

c.) Developmentally appropriate program for Preschool - What a child needs to learn depends on his psychological age. The preschool department of UECS understands this well and so they have developed series of teaching experiences for the kids that will enhance their growth towards a fully mind, heart and body.

d.) Basic Education Curriculum for Elementary and secondary School - The BEC curriculum proves to be appropriate in its approach and content in making the students ready to face real life situations and challenges.

e.) Chinese Language - As on of the growing languages in the world, second to English, the school provides Chinese language as elective for elementary and high school.

f.) Child-friendly environment - The operates in the general idea that the premise and the people around the camps should be friendly and helpful for utmost learning and development.

g.) Low student-teacher ratio - Following the result of DepEd's study last 2005, that low student-teacher ratio promotes high academic performance for the students, the school maintains a number of as low as 8 students to a maximum of 23 students per class.

2.) Teacher and Administrator Development

a.) Christian, effective, efficient \& dedicated teachers and staff - All teachers and staff of the school are

Christian. But not only this. They are also effective, efficient and dedicated, able to meet the standard set by DepEd. Everyone is encouraged to have professional development by taking up masters and doctoral study, as some of them are already taking. This year, the school become research-oriented and the proof is shown in the attendance of two of their faculty as parallel speakers in the National Seminar/Workshop hosted by UP Diliman.

3.) Physical Plant/Facilites Development

a.) Good facilities (fully Air-conditioned Rooms) - Students will be comfortable to study with the fully airconditioned rooms, from preschool to high school.

b.) Sports Facilities and Training - The all-purpose gym serves as a basketball court and a venue for different sports and training event. Front of the school, the playground is set for the children to enjoy during physical education class and leisure time after class hour.

4.) School-Community Partnership

a.) parental/students counseling - The guidance services include parental/students counseling. The school believes in that the collaboration of the school, parents, peers and students is very important for the total growth and development of the child.

b.) Parent-Teacher Fellowship - The Family Day, Foundation Day, Chinese Week, and departmental convocations are some of the events where parents, teachers and students experience meaningful fellowship. c.) Parenting Seminars - Having its existence because of the church, the school has its programs for parents like seminars. 
Resource Generation and Fund Management - Funds are generally coming from tuition fees, although supporsts also come from the church specially for teacher's love gift and for special occasions. The finance officer has her job to allocate funds for one year activities and needs.

\subsection{Statement of the Problem}

This study is designed to find out the relationship of organizational behavior and the emotional quotient of the students in United Evangelical Church School, Sta. Cruz, Laguna.

Specifically, it seeks to answer the following questions:

1.) What is the profile of multiple intelligences of the students in UECS?;

2.) What is the profile of learning style of the students in UECS?;

3.) What is the mean level of emotional quotient of the students in UECS in terms of the following dimensions?:
a.) Self-awareness;
b.) Self-regulation;
c.) Motivation;
d.) Empathy;
e.) Social Skills;

4.) What is the kind of organizational behavior exhibited by staff and employees at UECS; and

5.) Is there a significant relationship between each of the dimensions of emotional quotient (self-awareness, selfregulation, motivation, empathy and social skills) and the perceived organizational behavior at UECS?

\subsection{Significance of the Study}

This study on organizational behavior, emotional quotient level, multiple intelligences and learning styles will benefit the following groups of person:

1.) Class advisers - The class advisers have direct access to their advisory class. They usually have the longest time with their advisory class than any other authority in the school. Therefore, they have the greatest opportunity to be of help with regards to the emotional aspect of the students. Knowing the students' emotional quotient level through this study will guide them in leading the students towards maturity when it comes to that aspect.

2.) Club advisers - The multiple intelligences test will highlight the specific talent/s and inclination of the students that they can develop in themselves. The club advisers of Math, English, Theater Arts and other upcoming clubs can tap these students based on their multiple intelligences.

3.) Subject teachers - Knowing the learning style of the students can lead to the teachers' better understanding of how the students acquire knowledge. Through this study, the teachers can adjust their approach based on the learning style of specific students or majority of the students in a class.

4.) Students and Parents - Students and parents are the indirect beneficiaries of this study. Once the class advisers, club advisers and subject teachers have been informed of the result of the study, the students will benefit specially in terms of emotional maturity, development of skills and talents, and increase in academic performance. Parents will understand more of their child/children and will have a clear view on how they can be of help to the school in fulfilling its mission and vision.

5.) Employee and Staff of UECS - Because the possible relationship of emotional quotient of students to organizational behavior will be revealed, employee and staff of UECS can adjust on the organizational climate needed to promote growth and development in terms of emotional quotient of students which is needed for their future success.

6.) Board of Elders and Deacons of UECS - Leaders of school and church play an important part in giving guidance towards the fulfillment of the school's mission and vision. Therefore, they need to be aware of the organizational behavior existing within UECS as related (or not related) to the emotional quotient of the students. In this manner, they will be able to effectively guide the development of the school towards meeting their objectives and meeting clients' demands.

7.) The Community - The immediate environment surrounding the school is not just the primary source of clients of the school but also the beneficiary of the continued effort of the institution in bringing out the best in individual lives. Knowing the effect or relationship or organizational behavior to the emotional quotient of the child will make them aware of the importance of being part of having good communication with school authorities and in doing so, being part of the mission of the school in providing quality education and bringing out excellence in character.

8.) Readers and Researchers - Future research may be done to explore more or conduct deeper study on the same subject. This paper may guide readers and researchers in doing so. Result of the study may differ in what they can 
obtain. Nevertheless, the writer believes that this can be a good foundation in related studies that can be degleg in the future.

\subsection{Scope and Limitation}

This study will only involve grade four students up to fourth year high school. Students of that age are able to grasp things about their emotions, their inclination to different skills and talents, and how they want things to be presented to them. Revision of the instruments is still needed so that these can be administered to grades one to three.

Since more and more studies are being conducted with regards to organizational behavior, the instrument used here in determining organization's behavioral style may not be suited for other organizations or companies. Revision of the instrument may be required if it will be used in a different setting.

\section{Conceptual Framework}

This chapter contains review of related literature concerning organizational behavior, emotional quotient, multiple intelligences and learning styles. It also includes the hypotheses, paradigm and definition of terms that will help readers understand better the basis and foundation of the present study.

\subsection{Organizational Behavior}

It is surprising to note that the history of the study and development of organizational behavior can be traced back in the Reformation and Protestantism. Wertheim (2007?) puts it this way, "A new ethic began to evolve... embodied in quotes from Luther ("All men possess a calling in the world and the fulfillment of its obligation is a divinely imposed duty") and Calvin ("Disciplined work raises a person above the calling into which he was born and is the only sign of his election by God to salvation")... Over time, the Protestant Reformation provided an ideological foundation for the modern industrial society by suggesting that work is now a profound moral obligation, a path to eternal salvation. The focus is this world and materialism, not next world. The individual's obligation is self-discipline, and systematic work. It should be clear that the factory system which began to evolve late in the 18th Century could never have flourished without the ideological underpinnings of this profound shift in philosophy as exemplified by the Protestant Ethic."

From Wertheim's writing, the impact of the Protestant Reformation on work can be summarized as follows:

- Work is a profound moral obligation and is not just a means of living;

- The focus of work is the present, although it has significance in the future;

- One must learn self-discipline and systematic work; and

- On goal of work is to help the weak, but it emphasizes that poverty is a sink where a one should rise and not stay.

From Organizational Behavior (2007), it can be deduced that this field of study can be broken down into two sub-areas:

1.) Micro Organizational Behavior - The study of how individuals and groups affect and are affected by organizations. Drawing primarily on psychology, this area includes such topics as cognition, decision making, learning, motivation, negotiation and bargaining, cooperation and altruism, emotions, impressions management, group processes, stereotyping and injustice, power and influence.

2.) Macro Organizational Behavior - The study of organizations as systems, relations among organizations, and organizational environments, drawing primarily on sociology, this area includes such topics as organizational structure and demography, technology, culture, organizational change, employment relations, organizational networks, and environmental demands and constraints. Both public- and private-sector organizations are analyzed, as are organizations in other countries.

According to Clark (2007) there are four models of organizational behavior:

- Autocratic - The basis of this model is power with a managerial orientation of authority. The employees in turn are oriented towards obedience and dependence on the boss. The employee need that is met is subsistence. The performance result is minimal.

- Custodial - The basis of this model is economic resources with a managerial orientation of money. The employees in turn are oriented towards security and benefits and dependence on the organization. The employee need that is met is security. The performance result is passive cooperation.

- Supportive - The basis of this model is leadership with a managerial orientation of support. The employees in turn are oriented towards job performance and participation. The employee need that is met is status and recognition. The performance result is awakened drives. 
- Collegial - The basis of this model is partnership with a managerial orientation of teamwork. The employees in $₫ \not 410$ oriented towards responsible behavior and self-discipline. The employee need that is met is self-actualization. The performance result is moderate enthusiasm.

Whenever there's discontinuity in work, it can be considered as 'change.' Knoster, Villa, \& Thousand (2000) proposed a popular change framework:

Vision -> Skills $->$ Incentives $->$ Resources $->$ Action Plan = Change

- A vision is the starting point for goals. It provides the launch pad for action and the parameters for problem-solving.

- Once a vision is established, it is necessary to build skills needed to realize the vision.

- Incentives help to motivate the workforce to acquire and maintain new skills. Building "buy-in" engages them -- it means they are now stake-holders.

- Adequate resources allow the vision to be achieved.

- Action Planning is a continuous thread across all phases -- it is change process. Although presented as the final component of the change framework, it should be viewed as the foundation of the systems change process.

Many theories regarding work has already been practiced in different fields like manufacturing companies, sales, advertisement, finance firms and schools. PsycInfo. American Psychological Association (2005) declares that "more than ever, conducting business in the 21 st century involves an understanding of the complex psychological processes related to human attitudes, knowledge, and behavior in organizations."

Even in aircraft and navy teams, organizational behavior is also considered to gain sure success in any mission and project. In Modeling Human and Organizational Behavior (1998), the researcher declared this, "Both for training and command decision aiding, the behaviors that are important to represent realistically are those that can be observed by the other participants in the simulation, including physical movement and detection and identification of enemy forces. It is important that observable actions be based on realistic decision making and that communications, when they originate with a simulated unit, be interpretable as the result of sensible plans and operations."

Because of increasing interest in the field of study and the changing demand for a successful business enterprise for the $21^{\text {st }}$ century Borgatti (2002) in his 'Global Trends in or Affecting Organizational Structures in the 21st Century' came up with the following model of work, with the different factors interacting with each other towards globalization, diversity and flexibility.

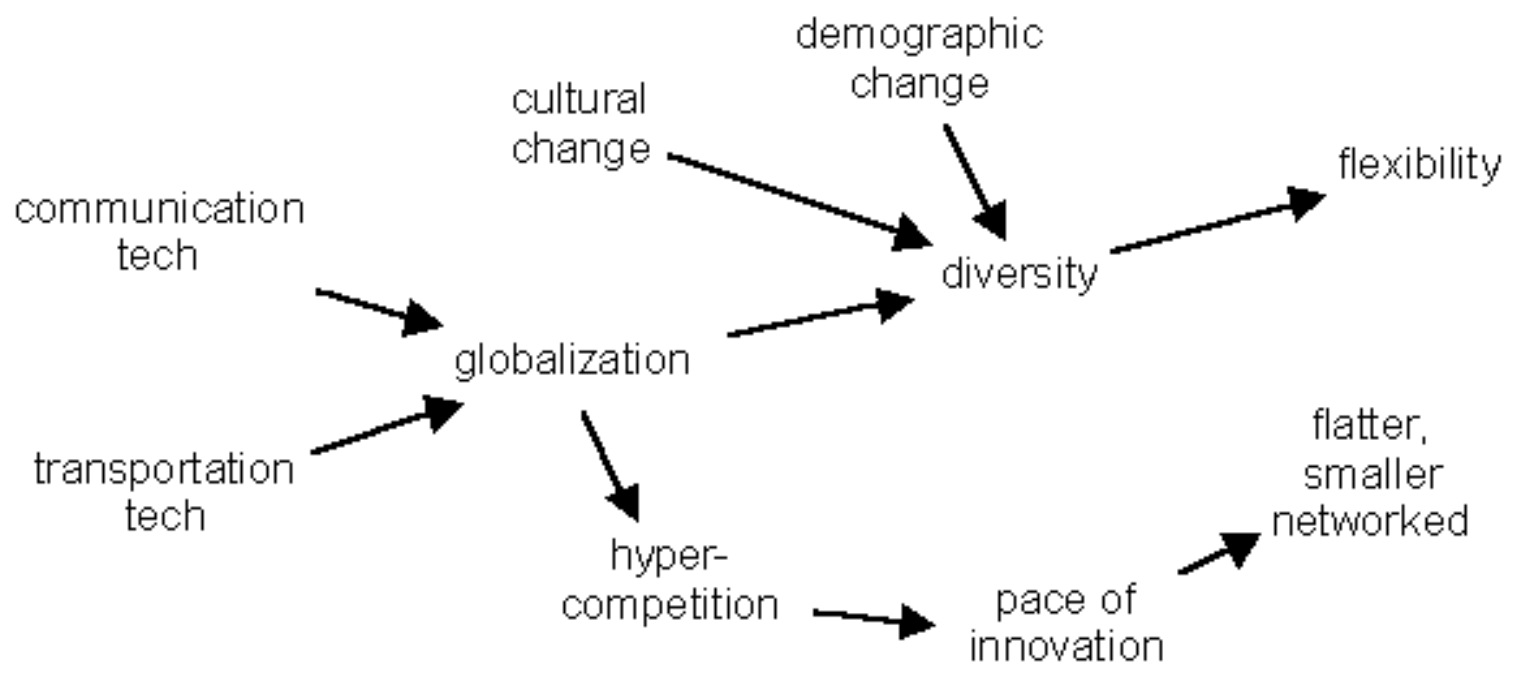

According to him, "organizations that flatten tend to simultaneously encourage horizontal communication among workers. Rather than work through the hierarchy, it is often faster for workers that need to coordinate with each other to simply communicate directly."

Because of globalization, managers and leaders learn how to deal with different groups of people with different nationality. Borgatti (2002) in his 'Differences in Cultures' emphasized that 'it is important to recognize that people from different cultures have are different in a variety of ways, including

- different ways of looking at things

- different ways of dressing

- different ways of expressing personality/goodness."

A comical, but intriguing and related insight to organizational behavior appeared in his article: 


\begin{tabular}{|l|}
\hline In an ideal world ... \\
- the policemen would be English \\
- the car mechanics would be German \\
- the cooks would be French \\
- the innkeepers would be Swiss, \\
- and the lovers would be Italian \\
In a living hell ... \\
- the policemen would be German \\
- the car mechanics would be French \\
- the cooks would be English \\
- the innkeepers would be Italian \\
- and the lovers would be Swiss
\end{tabular}

Here, Borgatti (2002) is emphasizing that knowing well how a person behaves will give an edge to a manager or leader of an organization to maximize the potential of his subordinates.

All of these readings are important for this present study because they enumerate the development of organizational behavior throughout the century.

\subsection{Emotional Quotient}

Emotional Intelligence or emotional quotient (EQ) dates back to 1995 when Daniel Goleman proposed a behavioral model and published his study in his book entitled 'Emotional Intelligence'.

Psychologists agree that Intelligence Quotient (IQ) is a weak determinant of a person's success. There are wider areas in EQ than in IQ that determine how a person will become successful in the future. IQ has become a traditional measure of intelligence but it ignores essential behavioral and character elements. "We've all met people who are academically brilliant and yet are socially and inter-personally inept. And we know that despite possessing a high IQ rating, success does not automatically follow." (Chapman, 2006)

Goleman (1995), in his "Emotional Intelligence" specified five dimensions of EQ. They are the following:

1. Self-awareness--knowing your emotions, recognizing feelings as they occur, and discriminating between them

2. Mood management--handling feelings so they're relevant to the current situation and you react appropriately

3. Self-motivation--"gathering up" your feelings and directing yourself towards a goal, despite self-doubt, inertia, and impulsiveness

4. Empathy--recognizing feelings in others and tuning into their verbal and nonverbal cues

5. Managing relationships--handling interpersonal interaction, conflict resolution, and negotiations

Emotional Intelligence according to Goleman (1995) is a "master aptitude, a capacity that profoundly affects all other abilities, either facilitating or interfering with them." Therefore he suggested that teachers should give importance on discovering and developing the child's emotional intelligence as much as they (the teachers) give importance on scholastic performance.

One of the main functions of the school is to get the students ready in facing real life situations like looking for a job and working effectively in their chosen career. Cherniss (2006?) in his study declared that "there now is a considerable body of research suggesting that a person's ability to perceive, identify, and manage emotion provides the basis for the kinds of social and emotional competencies that are important for success in almost any job."

All these readings have significance to the present study as they describe the nature of Emotional Quotient and its part in the total development of a child.

\subsection{Multiple Intelligences}

The term "intelligence" may elicit different meanings or responses from different field of study and various subject matters. Gardner (1983) in his "Frames of Mind" defined intelligence as "the ability to solve problems, or to create products, that are valued within one or more cultural settings." According to him, each individual has seven intelligences, and they are the following:

1.) Linguistic intelligence involves sensitivity to spoken and written language, the ability to learn languages, and the capacity to use language to accomplish certain goals. This intelligence includes the ability to effectively use language to express oneself rhetorically or poetically; and language as a means to remember information. Writers, poets, lawyers and speakers are among those that Howard Gardner sees as having high linguistic intelligence. 
2.) Logical-mathematical intelligence consists of the capacity to analyze problems logically, carry out mathes operations, and investigate issues scientifically. In Howard Gardner's words, in entails the ability to detect patterns, reason deductively and think logically. This intelligence is most often associated with scientific and mathematical thinking.

3.) Musical intelligence involves skill in the performance, composition, and appreciation of musical patterns. It encompasses the capacity to recognize and compose musical pitches, tones, and rhythms. According to Howard Gardner musical intelligence runs in an almost structural parallel to linguistic intelligence.

4.) Bodily-kinesthetic intelligence entails the potential of using one's whole body or parts of the body to solve problems. It is the ability to use mental abilities to coordinate bodily movements. Howard Gardner sees mental and physical activity as related.

5.) Spatial intelligence involves the potential to recognize and use the patterns of wide space and more confined areas.

6.) Interpersonal intelligence is concerned with the capacity to understand the intentions, motivations and desires of other people. It allows people to work effectively with others. Educators, salespeople, religious and political leaders and counselors all need a well-developed interpersonal intelligence.

7.) Intrapersonal intelligence entails the capacity to understand oneself, to appreciate one's feelings, fears and motivations. In Howard Gardner's view it involves having an effective working model of ourselves, and to be able to use such information to regulate our lives.

The first two are ones that have been typically valued in schools (linguistic and logical-mathematical); the next three are usually associated with the arts (musical, bodily-kinesthetic and spatial); and the final two are what Howard Gardner called 'personal intelligences' (interpersonal and intrapersonal). (Smith, 2002)

Later, these seven intelligences developed into a wider spectrum. "Because our understanding of the brain and human behavior is constantly changing, the number of intelligences is expanding." (Educational Broadcasting Corporation.com, 2004)

Gardner and his colleagues had perceived the possibility of adding three more intelligences: naturalist intelligence, spiritual intelligence and existential intelligence. Out of these three, Gardner singled out naturalist intelligence as fit to be added to the previous seven. These additional intelligences were published in "Intelligence Reframed" (1999), also by Howard Gardner.

8.) Naturalist intelligence enables human beings to recognize, categorize and draw upon certain features of the environment. It 'combines a description of the core ability with a characterization of the role that many cultures value.'

The existential and spiritual intelligences are both under debate by psychologists. As for spiritual intelligence, stated that "there are problems, for example, around the 'content' of spiritual intelligence, its privileged but unsubstantiated claims with regard to truth value, 'and the need for it to be partially identified through its effect on other people." (Howard Gardner, 1999)

The Educational Broadcasting Corporation.com (2004) cited the generalization made by Gardner with regards to multiple intelligences.

- All human beings possess all nine intelligences (including existential intelligences) in varying amounts.

- Each person has a different intellectual composition.

- We can improve education by addressing the multiple intelligences of our students.

- These intelligences are located in different areas of the brain and can either work independently or together.

- These intelligences may define the human species.

Funderstanding.com (2001) discusses the impact of multiple intelligences to learning.

Curriculum--Traditional schooling heavily favors the verbal-linguistic and logical-mathematical intelligences. Gardner suggests a more balanced curriculum that incorporates the arts, self-awareness, communication, and physical education.

Instruction--Gardner advocates instructional methods that appeal to all the intelligences, including role playing, musical performance, cooperative learning, reflection, visualization, story telling, and so on.

Assessment--This theory calls for assessment methods that take into account the diversity of intelligences, as well as self-assessment tools that help students understand their intelligences.

All of these have significance to the present study specifically in limiting the multiple intelligences that will be part of the survey. The present paper included the eight most prominent multiple intelligences in knowing the inclination of the students.

\subsection{Learning Styles}

Utts (2006?) defined learning styles as "the way a learner receives, sorts, interacts with and processes information." According to her, there is around 80 instruments existing that represent a dozen different learning styles and theories. All of those show the individuals perceive and process information in very different ways.

Funderstanding.com (2001) stated one way of classifying learning styles. 


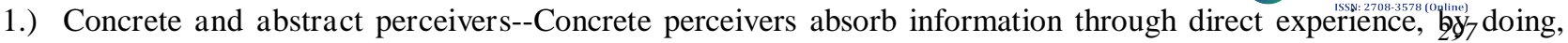
acting, sensing, and feeling. Abstract perceivers, however, take in information through analysis, observation, and thinking.

2.) Active and reflective processors--Active processors make sense of an experience by immediately using the new information. Reflective processors make sense of an experience by reflecting on and thinking about it.

Kakasenko (2002) categorized learning styles based on brain hemisphere.

1.) Left Hemispheric Children

a.) Behavioral Characteristics - task oriented, can sit still, memorizes, neat, orderly desk, follows directions, uses rote memory, is precisely organized, thinks in terms of black and white, is reality-based, is time-oriented, is focused, is logical, is controlled, is verbal, uses symbol, sequential

b.) Learning Styles - likes traditional teaching, likes lectures, will read chapters, likes outlining, is successful with phonics and decoding, enjoys worksheets, processes verbal information successfully

2.) Right Hemispheric Children

a.) Behavioral Characteristics - humorous, little sense of time, have a messy desk, often use fingers to count, are disorganized, are "on the move", have difficulty following directions, like to touch, poke, feel, are intuitive, are holistic, tend to be dramatic, are often athletic, are concrete, have trouble with phonics, are scattered, random

b.) Learning Styles - see the overall picture (the whole), like hands-on activities, tend to be better at analogies, like diagrams and patterns, find mnemonic (memory) devices fun and helpful, enjoy athletics and games, benefit from color-coded texts, go off in many directions, need visuals, films, movies, pictures, maps, benefit from taped lectures, a buddy to take notes, enjoy peer tutors, like tactile activities, learn when using dice, cards, board games, enjoy mind mapping instead of outlining, enjoy drama, music and art, may learn better when not constrained by a seat, are color sensitive

It's important for educators to understand the learning style of each of the students he's handling. "Individuals learn best in many different ways, sometimes using a variety of learning styles, but teachers and trainers may not always present information \& learning experiences in the ways that best suit you." (Hero.com, 2007).

Felder (2006?) highlighted the effect of educators' ignorance to the learning style of their students: "When mismatches exist between learning styles of most students in a class and the teaching style of the professor, the students may become bored and inattentive in class, do poorly on tests, get discouraged about the courses, the curriculum, and themselves, and in some cases change to other curricula or drop out of school."

These readings served as the basis of how the instrument for the present study was developed.

\subsection{Hypotheses}

1.) There is no relationship between organizational behavior and UECS students' self-awareness.

2.) There is no relationship between organizational behavior and UECS students' self-regulation.

3.) There is no relationship between organizational behavior and UECS students' motivation.

4.) There is no relationship between organizational behavior and UECS students' empathy.

5.) There is no relationship between organizational behavior and UECS students' social skills.

2.6. Paradigm

IV

MV

DV

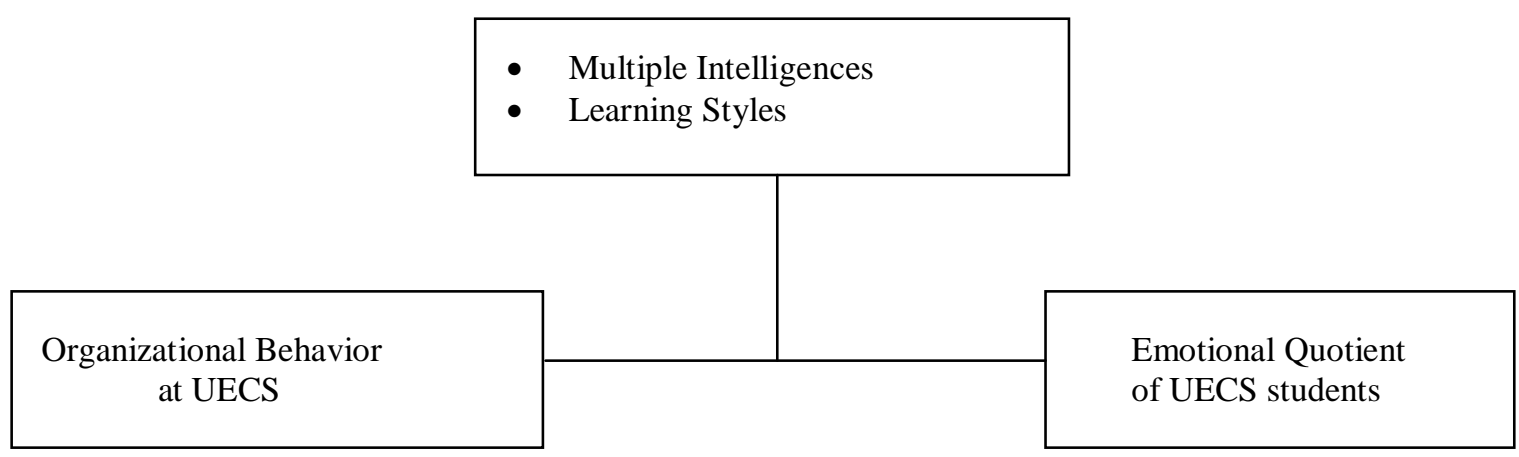


The following are definition of key terms used in this study. They are defined in three ways: how it is defined universally, how it is used in this study, and how it is measured.

Organizational Behavior - According to Wikipedia Free Encyclopedia (2007) refers to individual and group dynamics in an organizational setting. In this paper, organizational behavior is the study and application of how a person, as individual and as part of the organization, behaves in achieving the goal of an organization. It is measured through the organizational behavior survey given to faculty and employees of UECS.

Emotional Quotient - According to Wikipedia Free Encyclopedia (2007), emotional quotient (EQ) describes an ability, capacity, or skill to perceive, assess, and manage the emotions of one's self, of others, and of groups. In this paper, EQ is the maturity of an individual as to his emotions particularly in five areas: self-awareness, self-regulation, motivation, empathy and social skills. It is measured through the EQ assessment test given to the students as part of the guidance program.

Multiple Intelligences - Wikipedia Free Encyclopedia (2007) classifies Multiple intelligences (MI) as a psychological and educational theory put forth by psychologist Howard Gardner, which suggests that an array of different kinds of "intelligence" exists in human beings. In this research, MI is the theory that suggests that each individual has varying degree of eight intelligences: linguistic intelligence, bodily kinesthetic, intrapersonal, mathematical, musical, natulist, visual/spatial and interpersonal; and that each person is different from others. It is measured through a multiple intelligences test administered to the students as a part of the guidance program.

Learning Styles - Wikipedia Free Encyclopedia (2007) defines learning styles as the method of learning particular to an individual that is presumed to allow that individual to learn best. In this study, it is the orientation of the brain as to which part (left or right) is more functional during the learning process. It is measured through learning styles assessment test given to the students as part of the guidance program.

\section{Research Design and Methodology}

This chapter contains the design of the research, the population used in conducting the research, the procedures undertaken in securing valid data, the research instruments and the statistical treatment used in coming up with a meaningful interpretation of the data gathered.

\subsection{Research Design}

This study made use of a descriptive survey design where students were made to answer survey questions. Their response to these survey questions were recorded and taken as data necessary to answer the questions posed at the beginning of this study.

\subsection{Population}

Table 1 shows the number of pupils who participated in this study.

\begin{tabular}{|c|c|}
\hline Grade/Year & Number of Students \\
\hline Fourth Year & 15 \\
\hline Third Year & 12 \\
\hline Second Year & 24 \\
\hline First Year & 27 \\
\hline Grade 6 & 20 \\
\hline Grade 5 & 18 \\
\hline Grade 4 & 18 \\
\hline Total & 134 \\
\hline
\end{tabular}

Fourth year students is composed of 15 students, third year with 12 students, second year with 24 students (during the period of the study), first year with 27 students (during the period of the study), grade six with 20 students, grade five with 18 students, and grade four with 18 students. This produces a total of 134 students.

Also, there are 19 faculty and employees who participated in the organizational behavior survey. This comprises $70 \%$ of the total employee and staff of UECS. 
Permission to administer the exam was secured from the principal's office, and the three guidance tests were administered with the help of the advisers. They were done during devotion time where the emotional and mental state of the students were still relax and therefore, could give an honest and appropriate evaluation of themselves. Questions raised by the students were answered by the advisers and through supervision of the guidance counselor as she visited from room to room. The following are the schedule of the three guidance tests given to the students.

$\begin{array}{lll}\text { Emotional Quotient Level Test } & - & \text { June 8 } \\ \text { Learning Style Test } & - & \text { June } 14 \\ \text { Multiple Intelligences Test } & - & \text { June 20 }\end{array}$

The organizational behavior survey was administered last August 21, after a letter of request was given to the principal and was approved on that same date.

\subsection{Data Gathering Instrument}

For the Emotional Quotient, the instrument used was adopted from Daniel Goleman's book on working with Emotional Intelligence (1995). It contains 25 items representing the five dimensions of emotional intelligence, namely: self-awareness, self-regulation, motivation, empathy and social skills.

For the learning style, the researchers adopted the Learning Style Test that appeared on "Individual Education Plan.pdf' (Kakasendo, 2002). It contains 25 items that represents two learning styles based on brain hemisphere: Lest Hemispheric Learning Style and Right Hemispheric Learning Style.

For the Multiple Intelligences, the researchers made use of the assessment test that appeared on "Intelligence Reframed" (1999) by Howard Gardner. It contains 25 items representing the eight multiple intelligences, namely: linguistic Intelligence, bodily kinesthetic, intrapersonal, mathematical, musical, naturalist, visual/spatial and interpersonal.

The Organizational Behavior Survey was adopted from the work of Donald Clark (1998, ed. 2007). It contains 24 items which would elicit the mode that the organization prefers to operate in.

\subsection{Statistical Treatment}

Percentage was used to determine the profile of UECS students in the area of emotional quotient, multiple intelligences and learning styles. This answers sub-problem numbers one, two and three of the statement of the problem.

Simple mean was used to determine the organizational behavior of UECS. This answers sub-problem number four of the statement of the problem.

On the other hand, t-test was used to determine the relationship between the organizational behavior and the emotional quotient of the students in UECS. This answers sub-problem number five.

\section{Presentation, Analysis and Interpretation of Results}

This chapter the presents the data gathered in table and figure form. Analysis and interpretation also follows after each figure or table.

4.1. Multiple Intelligences

Figure 2. Multiple Intelligences of UECS Students

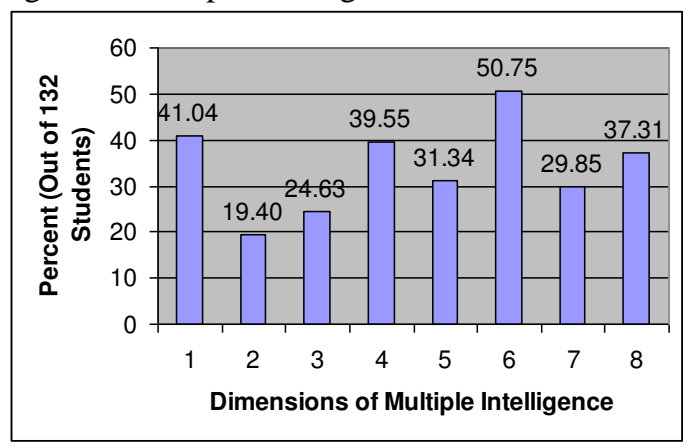


Figure 2 shows the distribution of multiple intelligences of UECS students. The eight dimensions of multiple intelligences are linguistic (1), kinesthetic (2) intrapersonal (3), mathematical (4), musical (5), naturalist (6), spatial (7) and interpersonal (8). Out of 134 students from grade 4 to fourth year, there are 55 students or $41.04 \%$ of the students have high linguistic skill; 26 students or $19.40 \%$ of the students have high kinesthetic skill; 33 students or $24.63 \%$ of the students have high intrapersonal skills; 53 students or $39.55 \%$ of the students have high mathematical skill; 42 students or $31.34 \%$ of the students have high musical skill; 68 students or $50.75 \%$ of the students have high naturalist skill; 40 students or $29.85 \%$ of the students have high spatial skill; and 50 students or $37.31 \%$ of the students have high interpersonal skill.

\subsection{Learning Styles}

Figure 3. Learning Styles of UECS Students

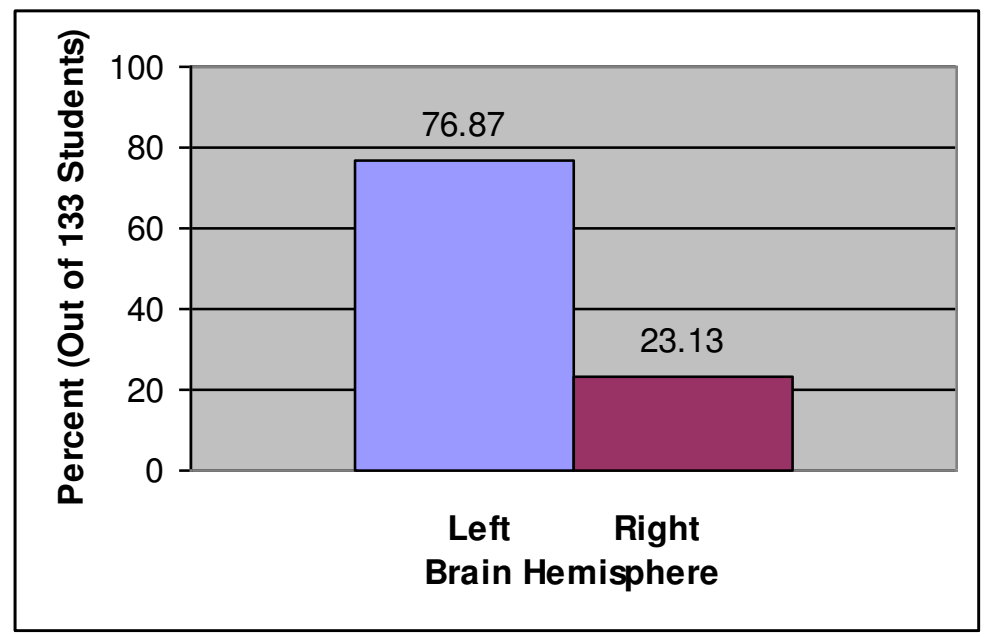

Figure 3 shows the learning styles of UECS students, from grade 4 to fourth year. Out of 134 students, there are 103 students or $76.87 \%$ of the students who are left brain hemispheric. On the other hand, there are 31 students or $23.13 \%$ of the students are right hemispheric.

\subsection{Emotional Quotient}

Figure 4. Emotional Quotient of UECS Students

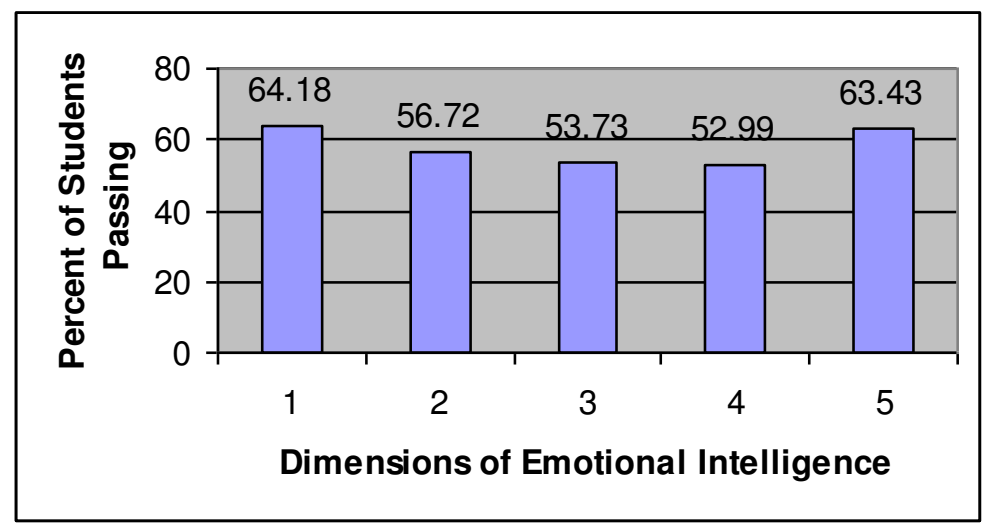

Figure 4 shows the emotional intelligence of UECS students. The five dimensions of emotional intelligence are selfawareness (1), self-regulation (2), motivation (3), empathy (4) and social skills (5). Out of 134 students from grade 4 to fourth year, 86 students or $64.18 \%$ of the students has adequate self-awareness skill; 76 students or $56.72 \%$ has adequate self- 
regulation skill; 72 students or $53.73 \%$ has high motivation; 71 or $52.99 \%$ has the ability to empathize; and 85 sty stydents or $64.43 \%$ has adequate social skills.

4.4. Organizational Behavior

Fig. 5 Organizational Behavior at UECS

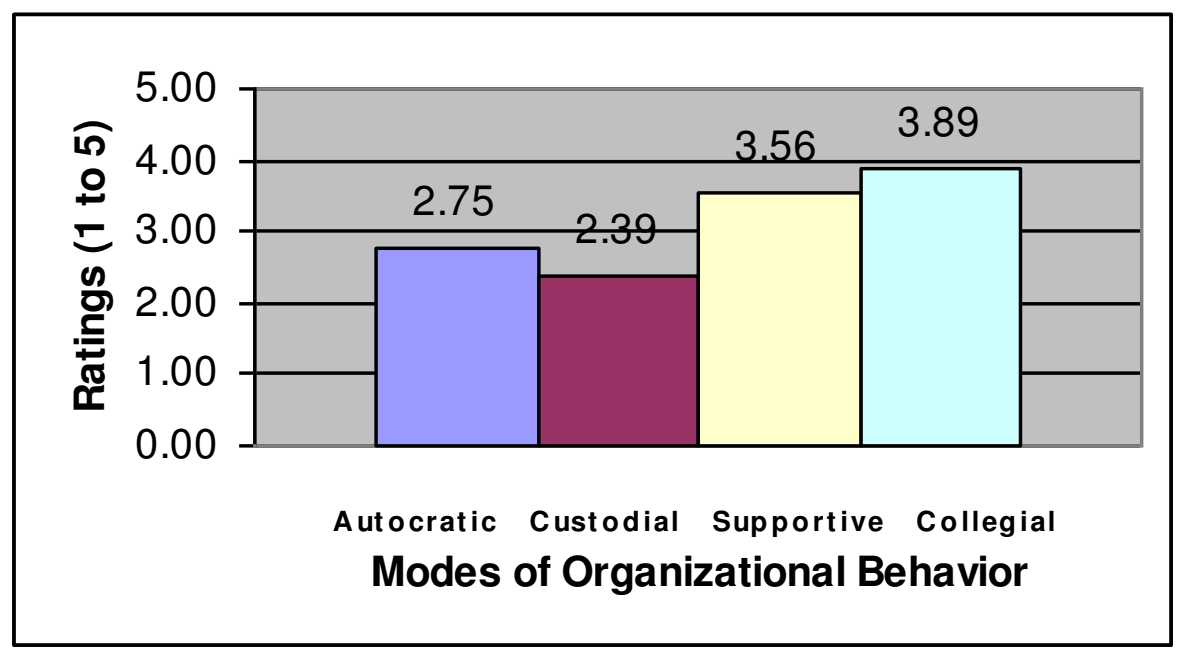

Figure 5 shows the organizational behavior at UECS as perceived by 19 faculty and employees. In a rate of 1 to 5 , they gave the school the following ratings: autocratic mode, 2.75 (occasional); 2.39 (seldom); 3.56 (frequent); and 3. 89 (frequent). It shows that UECS operates in a collegial mode, as evidenced by the highest average ratings. On the other hand, the organization least likely to operate in a custodial mode, as evidenced by the lowest average ratings.

\subsection{Organizational Behavior and Emotional Quotient (Self-Awareness)}

Table 1. Relationship of Organizational Behavior and Emotional Quotient (Self-Awareness)

\begin{tabular}{|l|r|r|}
\hline & Variable 1 & Variable 2 \\
\hline Mean & 3.885964912 & 3.315920398 \\
Variance & 0.259421702 & 0.411557501 \\
Observations & 19 & 134 \\
Pooled Variance & 0.393422108 & \\
Hypothesized Mean Difference & 0 & \\
Df & 151 & \\
t Stat & 3.707343907 & \\
t Critical one-tail & 1.655007509 &
\end{tabular}

Table 1 shows the relationship of organizational behavior at UECS and the students' emotional intelligence in the aspect of self-awareness. Since $t$ Stat $>t$ Critical $(3.71>1.66)$, the hypothesis which states that there is no significant relationship between organizational behavior and students' self-awareness, is rejected. In other words, there is a significant relationship between students' self-awareness and UECS organizational behavior. This means that when the organizational behavior is healthy, that is, the management and the faculty are in good terms and building strong partnership towards the attainment of the goal of the school, the self-awareness of the students are being developed and nurtured inside the school. 
Table 2. Relationship of Organizational Behavior to Emotional Quotient (Self-Regulation)

\begin{tabular}{|l|r|r|}
\hline & Variable 1 & Variable 2 \\
\hline Mean & 3.885964912 & 3.173134328 \\
Variance & 0.259421702 & 0.291002132 \\
Observations & 19 & 134 \\
Pooled Variance & 0.287237578 & \\
Hypothesized Mean Difference & 0 & \\
Df & 151 & \\
t Stat & 5.4256176 & \\
t Critical one-tail & 1.655007509 &
\end{tabular}

Table 2 shows the relationship of organizational behavior at UECS and the students' emotional intelligence in the aspect of self-regulation. Since t Stat $>$ t Critical $(5.43>1.66)$, the hypothesis which states that there is no significant relationship between organizational behavior and students' self-regulation, is rejected. In other words, there is a significant relationship between students' self-regulation and UECS organizational behavior. This means that when the organizational behavior is healthy, that is, the management and the faculty are in good terms and building strong partnership towards the attainment of the goal of the school, the self-regulation competency of the students are being developed and nurtured inside the school.

\subsection{Organizational Behavior and Emotional Quotient (Motivation)}

Table 3. Relationship of Organizational Behavior to Emotional Quotient (Motivation)

\begin{tabular}{|l|r|r|}
\hline & Variable 1 & Variable 2 \\
\hline Mean & 3.885964912 & 3.235074627 \\
Variance & 0.259421702 & 0.351279318 \\
Observations & 19 & 134 \\
Pooled Variance & 0.340329403 & \\
Hypothesized Mean Difference & 0 & \\
Df & 151 & \\
t Stat & 4.551363662 & \\
t Critical one-tail & 1.655007509 &
\end{tabular}

Table 3 shows the relationship of organizational behavior at UECS and the students' emotional intelligence in the aspect of social skills. Since t Stat $>$ t Critical $(4.55>1.66)$, the hypothesis which states that there is no significant relationship between organizational behavior and students' motivation, is rejected. In other words, there is a significant relationship between students' motivation and UECS organizational behavior. This means that when the organizational behavior is healthy, that is, the management and the faculty are in good terms and building strong partnership towards the attainment of the goal of the school, the motivation of the students are being developed and nurtured inside the school.

\subsection{Organizational Behavior and Emotional Quotient (Empathy)}

Table 4. Relationship of Organizational Behavior to Emotional Quotient (Empathy)

\begin{tabular}{|l|c|c|}
\hline & Variable 1 & Variable 2 \\
\hline Mean & 3.885964912 & 3.089552239 \\
Variance & 0.259421702 & 0.334175738
\end{tabular}


Table 4 shows the relationship of organizational behavior at UECS and the students' emotional intelligence in the aspect of empathy. Since t Stat $>$ t Critical $(5.70>1.66)$, the hypothesis which states that there is no significant relationship between organizational behavior and students' empathy, is rejected. In other words, there is a significant relationship between students' empathy and UECS organizational behavior. This means that when the organizational behavior is healthy, that is, the management and the faculty are in good terms and building strong partnership towards the attainment of the goal of the school, the empathy of the students are being developed and nurtured inside the school.

\subsection{Organizational Behavior and Emotional Quotient (Social Skills)}

Table 5. Relationship of Organizational Behavior to Emotional Quotient (Social Skills)

\begin{tabular}{|l|r|r|}
\hline & Variable 1 & Variable 2 \\
\hline Mean & 3.885964912 & 3.251865672 \\
Variance & 0.259421702 & 0.223915666 \\
Observations & 19 & 134 \\
Pooled Variance & 0.228148174 & \\
Hypothesized Mean Difference & 0 & \\
Df & 151 & \\
t Stat & 5.415420929 & \\
t Critical one-tail & 1.655007509 &
\end{tabular}

Table 5 shows the relationship of organizational behavior at UECS and the students' emotional intelligence in the aspect of social skills. Since t Stat $>$ t Critical $(3.71>1.66)$, the hypothesis which states that there is no significant relationship between organizational behavior and students' social skills, is rejected. In other words, there is a significant relationship between students' social skills and UECS organizational behavior. This means that when the organizational behavior is healthy, that is, the management and the faculty are in good terms and building strong partnership towards the attainment of the goal of the school, the social skills of the students are being developed and nurtured inside the school.

\section{Summary, Conclusions and Recommendations}

\subsection{Summary of Findings}

For this study, 134 students from grade four to fourth year have undergone series of tests to know their emotional quotient, multiple intelligences and learning styles. Simple mean and percentage were used obtain data for these three factors. On the other hand, 19 faculty/employees answered survey questions whose objective is to identify what behavioral model UECS prefers to operate in. Simple mean was used for this purpose. Afterwards, the relationship of organizational behavior to each of the dimensions of the emotional quotient of the students was measured using t-test.

Here are the findings that resulted out of this study:

1.) Out of 134 students from grade 4 to fourth year, there are 55 students or $41.04 \%$ of the students have high linguistic skill; 26 students or $19.40 \%$ of the students have high kinesthetic skill; 33 students or $24.63 \%$ of the students have high intrapersonal skills; 53 students or $39.55 \%$ of the students have high mathematical skill; 42 students or $31.34 \%$ of the students have high musical skill; 68 students or $50.75 \%$ of the students have high naturalist skill; 40 students or $29.85 \%$ of the students have high spatial skill; and 50 students or $37.31 \%$ of the students have high interpersonal skill. 
2.) Out of 134 students, there are 103 students or $76.87 \%$ of the students who are left brain hemispherifige 4 On the other hand, there are 31 students or $23.13 \%$ of the students are right hemispheric.

3.) Out of 134 students from grade 4 to fourth year, 86 students or $64.18 \%$ of the students has adequate selfawareness skill; 76 students or $56.72 \%$ has adequate self-regulation skill; 72 students or $53.73 \%$ has high motivation; 71 or $52.99 \%$ has the ability to empathize; and 85 students or $64.43 \%$ has adequate social skills.

4.) In a rate of 1 to 5, 19 faculty and employee of UECS gave the school the following ratings: autocratic mode, 2.75 (occasional); 2.39 (seldom); 3.56 (frequent); and 3. 89 (frequent).

5.) For the significant relationship between organizational behavior and emotional quotient:
a.) Self-awareness : t-Stat $>\mathrm{T}$-Critical
b.) Self-regulation : t-Stat $>$ T-Critical
c.) Motivation : t-Stat $>$ T-Critical
d.) Empathy : t-Stat > T-Critical
e.) Social Skills : t-Stat > T-Critical

\subsection{Conclusion}

Base on the findings that resulted out of this study, the following conclusions were formed.

1.) The most prevailing ability among the students of UECS students is naturalist ability, followed by kinesthetic and mathematical.

2.) Most of the students in UECS are left brain hemispheric.

3.) Most of the students in UECS have high EQ in two dimensions: self-awareness and social skills.

4.) It shows that UECS operates in a collegial mode, as evidenced by the highest average ratings. On the other hand, the organization least likely to operate in a custodial mode, as evidenced by the lowest average ratings.

5.) In relating organizational behavior to emotional quotient:

a.) since $\mathrm{t}$ Stat $>\mathrm{t}$ Critical, the hypothesis is rejected. This means that there is a significant relationship between students' self-awareness and UECS organizational behavior;

b.) since $\mathrm{t}$ Stat $>\mathrm{t}$ Critical, the hypothesis is rejected. This means that there is a significant relationship between students' self-regulation and UECS organizational behavior;

c.) since $\mathrm{t}$ Stat $>\mathrm{t}$ Critical, the hypothesis is rejected. This means that there is a significant relationship between students' motivation and UECS organizational behavior;

d.) since $\mathrm{t}$ Stat $>\mathrm{t}$ Critical, the hypothesis is rejected. This means that there is a significant relationship between students' empathy and UECS organizational behavior; and

e.) since $t$ Stat > t Critical, the hypothesis is rejected. This means that there is a relationship between students' social skills and UECS organizational behavior.

\subsection{Recommendations}

The conclusions made at the closing of this study paved way for the following recommendations:

1.) That class advisers study and be familiar with the emotional quotient of their advisory class so that they may guide them more effectively towards emotional growth and development;

2.) That club advisers tap those who has talents and skills the incorporate them in their group so that their ability will be nurtured and enhanced;

3.) That subject teachers know and be familiar with the learning style of each students so that they can develop learning experiences that will suit different learning styles;

4.) That students and parents continue to have good relationship at home. Parents should also be acquainted with their child's multiple intelligences, learning styles and emotional quotient, so that even at home, the development of the child that's happening inside the school may be extended at home;

5.) That employee and Staff of UECS continue to build partnership in fulfilling the school's mission and vision since it was found out that there is a significant relationship between organizational behavior and emotional quotient;

6.) That board of Elders and Deacons of UECS continue to promote collaborative effort between school management and faculty;

7.) That the community be aware also of the organizational behavior existing among them for they are the extension of the family and the school in making possible the total development of the child in their community; and

8.) That readers and researchers probe more on the same subject or on related subject, for this study has limitations also. 


\section{References}

Borgatti, Stephen P. (2002). Differences in Cultures.

Borgatti, Stephen P. (2002). Global Trends in or Affecting Organizational Structures in the 21st

Chapman, Alan. (2006). Emotional Intelligence (EQ), based on Daniel Goleman's EQ concept.

Cherniss, Cary. (2006). Graduate School of Applied and Professional Psychology, Rutgers 08854 .

Clark, Donald. (2007). Organizational Behavior Survey.

Educational Broadcasting Corporation.com. (2004). What is the theory of multiple intelligences

Felder, Richard. (2006). LEARNING STYLES, rmfelder@ mindspring.com.

Gardner, Howard. (1983). "Frames of Mind".

Gardner, Howard.(1999). "Intelligence Reframed". p.59.

Goleman, Daniel. (1995). "Emotional Intelligence”, p. 80.

Hero.com. (2007). Learning styles.

Kakasendo, Edna. (2002). "Individual Education Plan.pdf"

Knoster, T., Villa, R., \& Thousand, J. A (2000). Framework for thinking about systems change. In R. Villa \& J. Thousand (Eds.), Restructuring for caring and effective education: Piecing the puzzle together (pp. 93-128). Baltimore: Paul H. Brookes

Century

University, 152 Frelinghuysen Road, Piscataway, NJ

Modeling Human and Organizational Behavior. (1998). Application to Military Simulations Publishing Co. Education (CBASSE).

Organizational Behavior. (2007). Stanford Graduate School of Business.

PsycInfo. (March 2005). American Psychological Association. Printed in the United States of America.

Smith, M. K. (2002). Howard Gardner and multiple intelligences, the encyclopedia of informal education, http://www.infed.org/thinkers/gardner.htm.

Utts, Jessica. (2006). "Recognizing and Valuing Variability In Our Students and Ourselves." Department of Statistics University of California, Davis. jmutts@ucdavis.edu.

Wertheim, Edward G. (2007). Historical Background of Organizational Behavior (prepared by Professor, College of Business Administration, Northeastern University, Boston, MA 02115). 